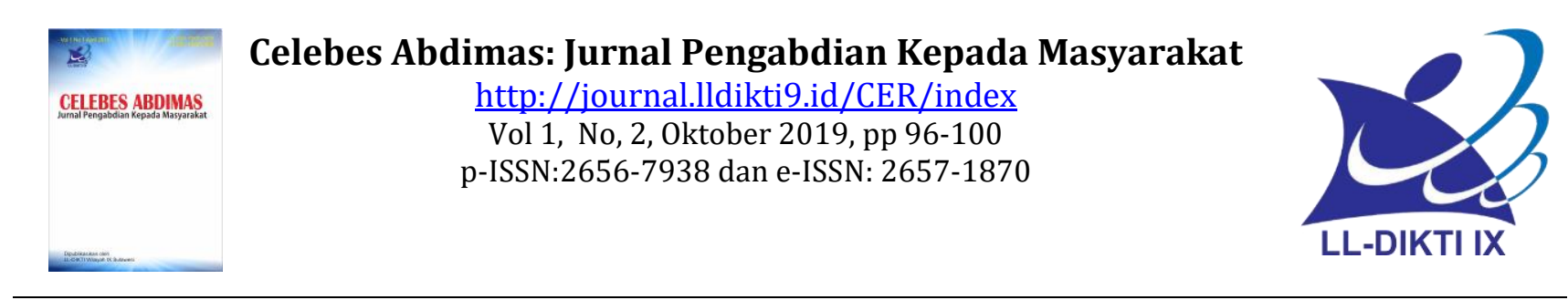

\title{
Penerapan Tanaman Daun Gedi Merah Sebagai Pengobatan Tradisional Antikanker Payudara di Desa Maku Provinsi Sulawesi Tengah
}

\author{
Viani Anggi \\ Program Studi D-III Farmasi, Sekolah Tinggi Ilmu Farmasi Pelita Mas Palu \\ Email: viani.anggi@gmail.com
}

\section{Artikel info}

\section{Artikel history:}

Received;September-2019

Revised: September-2019

Accepted;Oktober-2019

Publish: Oktober-2019
Abstract. This service activity aims to apply the results of research to the community in Maku Village on the Benefits of Red Gedi Plants in traditional anticancer breast medicine. The method used in the service is counseling and demonstration methods for the use of red gedy plants as a traditional anticancer breast treatment. As for the results obtained from this community service activity, the community in Maku Village can understand the concept of applying red gedy as a traditional anticancer breast treatment with an evaluation level of understanding of $80 \%$ and the community can apply red gedy plants in the form of dried simplicia steeping from red gedi plants can be used as a traditional anticancer treatment of breast by $75 \%$.

Abstrak. Kegiatan Pengabdian masyarakat ini bertujuan untuk menerapkan hasil penelitian kepada masyarakat di Desa Maku tentang Manfaat Tanaman Gedi Merah dalam pengobatan tradisional antikanker payudara. Metode yang digunakan pada pengabdian yaitu metode penyuluhan dan demonstrasi untuk penggunaan tanaman gedi merah sebagai pengobatan tradisional antikanker payudara. Adapun hasil yang diperoleh dari kegiatan pengabdian ini yaitu Masyarakat di Desa Maku dapat memahami konsep penerapan tanaman gedi merah sebagai pengobatan tradisional antikanker payudara dengan evaluasi tingkat persentase pemahaman sebesar $80 \%$ dan masyarakat dapat mengaplikasikan tanaman gedi merah dalam bentuk seduhan simplisia kering dari tanaman gedi merah yang dapat digunakan sebagai pengobatan tradisional antikanker payudara sebesar $75 \%$.

Coresponden author:

Viani Anggi

Program Studi D-III Farmasi, STIFA Pelita Mas Palu Email: viani.anggi@gmail.com

tanaman Gedi

merah;

antikanker

payudara.

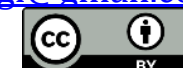

artikel dengan akses terbuka dibawah lisensi CC BY -4.0 


\section{PENDAHULUAN}

Prevalensi penyakit kanker setiap tahunnya terus bertambah dan meningkat tinggi pada golongan pendidikan tinggi ((Kementrian Kesehatan RI Pusat Data dan Informasi Kesehatan, 2015). Menurut Organisasi Badan Kesehatan Dunia (WHO) 8-9\% wanita mengalami kanker payudara (World Health Organization|International Agency for Research on Cancer- Global Cancer Observatory, 2018). Perkiraan American Cancer Society tahun 2014 untuk kanker payudara di Amerika Serikat untuk tahun 2016 adalah 246.660 kasus, di Indonesia $1.4 \%$ kanker meningkat seiring dengan bertambahnya usia (Siegel, Miller, \& Jemal, 2016).

Bahan alam memiliki potensi untuk dikembangkan sebagai agen kemoterapi kombinasi dengan doxorubicin sebagai obat kimia. Tanaman Daun gedi merah terkenal dan disukai oleh masyarakat kota Palu sebagai salah satu menu sayuran favorit, karena merupakan tanaman multi guna, padat nutrisi dan berkhasiat sebagai obat. Daun gedi merah (Abelmochus manihot (L.) Medik) mengandung metabolit sekunder yakni flavonoid $(722,5 \mathrm{mg} / \mathrm{Kg})$. Dari hasil penelitian yang ditemukan (Taroreh, Raharjo, Hastuti, \& Murdiati, 2016) menyatakan bahwa kandungan flavonoid daun gedi merah secara ekstraksi maserasi tergolong tinggi, selain itu nilai $\mathrm{IC}_{50<50} \mathrm{mg} / \mathrm{ml}$ (Waris, Dewi Pratiwi, \& Najib, 2016).

Menurut (Li, Zhang, \& Wang, 2016), mengatakan bahwa tanaman gedi merah (Abelmochus manihot (L.) Medik) merupakan tanaman tropis yang berasal dari Cina yang dikenal dengan nama Gedi. Di kota Palu tanaman ini digunakan sebagai sayuran. Tanaman ini dipercaya memiiiki khasiat sebagai obat karena kaya akan vitamin A, B1, B2: B3, C, E dan kalsium, kalium, tembaga, zink serta kolagen serta berbagai senyawa sekunder seperi flavonoid, saponin dan senyawa fenolit yang memiliki aktivitas penangkal radikal bebas dan hidrogen peroksida (Biosci et al., 2013). Kandungan flavonoid dari daun gedi merah dapat memiliki aktivitas sebagai agen antikanker. Peran flavonoid untuk pencegahan kanker dan uji klinis pada manusia menunjukkan bahwa flavonoid memiliki efek utama pada kemoprevensi kanker dan kemoterapi (Daun et al., 2010).

Dari hasil penelitian Viani, 2018 terhadap tanaman gedi merah asal kota Palu Sulawesi Tengah didapatkan hasil bahwa tanaman gedi merah memiliki antioksidan aktivitas penangkapan radikal bebas DPPH $\mathrm{IC}_{50}$ didapatkan hasil 3,45 $\mu \mathrm{g} / \mathrm{ml}$, dengan hasil uji kuantitatif ekstrak Daun gedi merah (Abelmochus Manihot L. Medik) didapatkan hasil untuk kandungan flavonoid yaitu $2,3 \% \mathrm{~b} / \mathrm{b}$, alkaloid mengandung $0,09 \% \mathrm{~b} / \mathrm{b}$ dan kandungan tanin yaitu $63,60 \%$ b/b. Selain itu didapatkan hasil bahwa ekstrak N-Heksan daun gedi merah (Abelmochus Manihot L. Medik) bersifat cukup aktif terhadap kehidupan sel kanker payudara 4T1 dan memiliki potensi untuk dikombinasi dengan agen sitotoksik Doxorubicin pada kultur sel kanker payudara $4 \mathrm{~T} 1$.

Berdasarkan latar belakang diatas, maka perlu dilakukan penyuluhan dan demonstrasi pemahaman masyarakat di Desa maku tentang penerapan tanaman gedi merah sebagai pengobatan tradisional antikanker payudara dan mengaplikasikan tanaman gedi merah dalam seduhan simplisia kering. Adapun Tujuan kegiatan pengabdian ini yaitu diharapkan dapat memberikan pengetahuan kepada masyarakat di Desa maku tentang penerapan tanaman gedi merah sebagai pengobatan tradisional antikanker payudara, sehingga penggunaan tanaman tradisional dari bahan alam dapat dipahami dengan baik dan benar.

\section{Metode}

Metode yang digunakan pada pengabdian kepada masyarakat berupa penyuluhan dan Demonstrasi pada masyarakat yang ada di Desa Maku Kabupaten Sigi Biromaru Provinsi Sulawesi Tengah sebanyak 30 peserta. Dalam melaksanakan pengabdian dengan tema "Penerapan Tanaman Gedi Merah sebagai Pengobatan tradisional antikanker payudara" dilakukan melalui beberapa tahapan: yang pertama melakukan strategi penyusunan rencana penyuluhan/ ceramah.; terstruktur standar yang digunakan dalam pengabdian, dasar dan 
output hasil penyuluhan, terstruktur materi penyuluhan tentang tanaman gedi merah, terstruktur lokasi, waktu dan tempat pengabdian, terstruktur alat pembelajaran yang digunakan dalam pelaksanaaan pengabdian dalam bentuk power point dan kumpulan buku Tanaman obat keluarga. Selanjutnya pelaksanaan pengabdian seperti Penyuluhan ceramah tentang defenisi tentang kanker payudara, gejala yang dirasakan, manfaat dari tanaman gedi merah sebagai antikanker payudara serta penerapannya dalam sediaan simplisia serbuk kering dari tanaman gedi merah asal kota Palu Sulawesi tengah dan terakhir melakukan evaluasi kegiatan pengabdian kepada masyarakat di Desa Maku Kecamatan Biromaru Sulawesi Tengah terhadap tingkat pengetahuan masyarakat terhadap penerapan tanaman gedi merah sebagai antikanker payudara sebelum dan sesudah kegiatan pengabdian.

\section{Hasil Dan Pembahasan}

Hasil pelaksanaan kegiatan pengabdian kepada masyarakat yang dilakukan di Desa Maku Kecamatan Sigi Biromaru Provinsi Sulawesi Tengah dengan judul "Penerapan Tanaman Daun Gedi Merah Sebagai Pengobatan Tradisional Antikanker Payudara". Kegiatan Pengabdian kepada masyarakat dilakukan dengan beberapa langkah, yang dimulai dari respon surat dari Desa Maku ke LPPM Institusi, selanjutnya dilakukan tahapan persiapan, pelaksanaan dilapangan sampai respon hasil dari evaluasi tingkat pengetahuan masyarakat sebelum dan sesudah kegiatan pengabdian kepada masyarakat dilaksanakan.

Adapun langkah awal yang dilakukan dalam melaksanakan kegiatan pengabdian ini yaitu strategi dalam melakukan penyusunan rencana penyuluhan/ ceramah.; terstruktur standar yang digunakan dalam pengabdian, dasar dan output hasil penyuluhan, terstruktur materi penyuluhan dan demonstrasi tentang tanaman gedi merah dengan durasi waktu 240 menit, terstruktur lokasi, waktu dan tempat pengabdian, terstruktur alat pembelajaran yang digunakan dalam pelaksanaaan pengabdian dalam bentuk power point dan kumpulan buku Tanaman obat keluarga.

Pelaksanaan kegiatan pengabdian kepada masyarakat dilaksanakan pada hari minggu, 02 Desember 2018 di Kelurahan Desa Maku kecamatan Biromaru Provinsi Sulawesi Tengah, dengan waktu kegiatan berlangsung pada pukul 08.00 hingga pukul 12.00 dan jumlah peserta pengabdian 30 peserta. Pelaksanaan kegiatan pengabdian kepada masyarakat dimulai dari pemaparan tentang defenisi penyakit kanker, gejala yang dirasakan, manfaat dan kandungan dari tanaman gedi merah sampai pada demonstrasi pembuatan seduhan simplisia kering dai tanaman gedi merah asal kota Palu Sulawesi Tengah. Adapun kegiatan pengabdian kepada masyarakat dapat berjalan sesuai dengan target diawal.

Tahapan akhir yang dilakukan setelah pengabdian yaitu melakukan evaluasi dari penyuluhan dan demonstrasi penerapan tanaman gedi merah sebagai antikanker payudara berdasarkan feedback yang diberikan dari peserta pengabdian dan dari hasil evaluasi didapatkan hasil bahwa masyarakat di Desa Maku dapat memahami konsep penerapan tanaman gedi merah sebagai pengobatan tradisional antikanker payudara dengan evaluasi tingkat persentase pemahaman terdapat peningkatan sebesar $80 \%$ setelah kegiatan dan masyarakat juga dapat mengaplikasikan tanaman gedi merah dalam bentuk seduhan simplisia kering dari tanaman gedi merah yang dapat digunakan sebagai pengobatan tradisional antikanker payudara dengan peningkatan sebesar $75 \%$ setelah kegiatan pengabdian

Berdasarkan evaluasi pengabdian kepada masyarakat di Desa Maku Kecamatan Sigi Biromaru Provinsi Sulawesi Tengah dengan judul "Penerapan Tanaman Daun Gedi Merah Sebagai Pengobatan Tradisional Antikanker Payudara" didapatkan hasil sebagai berikut : Peserta Pengabdian kepada masyarakat dapat mengetahui tentang deteksi dini penyakit kanker payudara berdasarkan gejala yang timbul (World Health Organization|International Agency for Research on Cancer- Global Cancer Observatory, 2018), Peserta kegiatan pengabdian kepada masyarakat dapat memahami tentang manfaat dan kandungan dari tanaman gedi merah yang dapat digunakan sebagai pengobatan tradisional dengan berbagai manfaat diantaranya selain sebagai antikanker juga dapat digunakan sebagai antivirus (Wu, Yang, Huang, Liu, \& Wu, 2007), Peserta kegiatan dapat membuat tanaman obat keluarga (TOGA) dari tanaman gedi merah, 
99 | Celebes Abdimas : Jurnal Pengabdian Kepada Masyarakat

selain itu juga peserta pengabdian dapat mengaplikasikan tanaman gedi merah dalam seduhan simplisia kering yang dapat digunakan kapan saja sebagai pengobatan tradisional (Jet S Mandey, Hendrawan Soetanto, Osfar Sjofjan, \& Bernat Tulung, 2014).

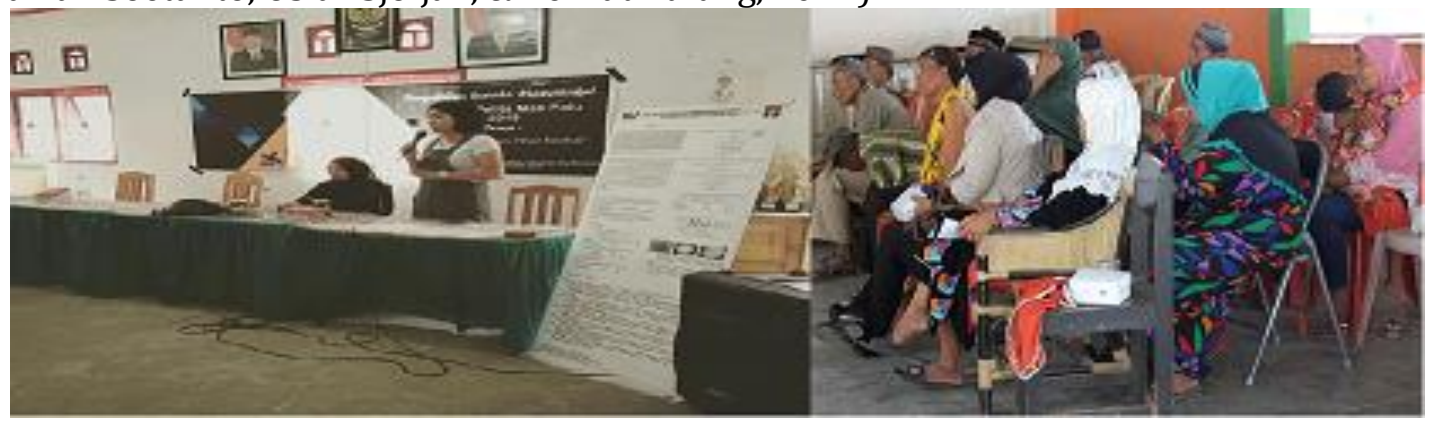

Gambar 1. Penyuluhan Penerapan Tanaman Gedi Merah sebagai Antikanker Payudara

Tabel 1. Persentase tingkat Pengetahuan masyarakat di Desa Maku Tentang Tanaman Gedi Merah sebagai Antikanker payudara

\begin{tabular}{lcc}
\hline Test Parameters & $\begin{array}{c}\text { Sebelum Kegiatan } \\
\text { Pengabdian \% }\end{array}$ & $\begin{array}{c}\text { Setelah Kegiatan } \\
\text { Pengabdian \% }\end{array}$ \\
\hline $\begin{array}{l}\text { Tingkat Pengetahuan } \\
\text { masyarakat tentang } \\
\text { tanaman Gedi Merah }\end{array}$ & & \\
$\begin{array}{l}\text { Tingkat Pengetahuan } \\
\text { masyarakat tentang } \\
\text { seduhan simplisia kering } \\
\text { dari tanaman Gedi Merah }\end{array}$ & 20 & 80 \\
\hline
\end{tabular}

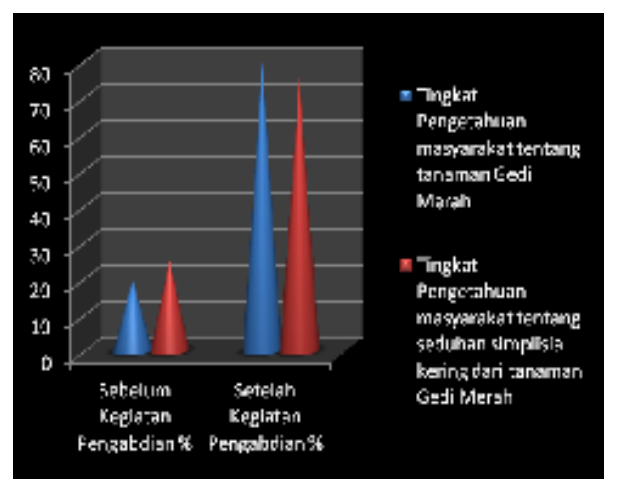

Gambar 2. Grafik Peningkatan Pengetahuan tentang hasil hasil Penerapan Tanaman Gedi merah sebagai Antikanker Payudara 


\section{Simpulan Dan Saran}

Dari hasil pengabdian dapat disimpulkan yaitu Masyarakat di Desa Maku dapat memahami konsep penerapan tanaman gedi merah sebagai pengobatan tradisional antikanker payudara dengan evaluasi tingkat persentase pemahaman sebesar $80 \%$ dan masyarakat dapat mengaplikasikan tanaman gedi merah dalam bentuk seduhan simplisia kering dari tanaman gedi merah yang dapat digunakan sebagai pengobatan tradisional antikanker payudara sebesar $75 \%$. Saran dari kegiatan ini yaitu diperlukan kegiatan rutin untuk membentuk tim Tanaman obat tradisional Desa agar penyuluhan Tanaman obat tradisional dapat berkesinambungan.

\section{Daftar Rujukan}

Biosci, I. J., Mandey, J. S., Soetanto, H., Sjofjan, O., Tulung, B., Student, P. G., \& Java, T. E. (2013). The effects of native gedi leaves (Abelmoschus manihot L. Medik.) of Northern Sulawesi-Indonesia as a Source of Feedstuff on the Performance of Broilers. International Journal of Biosciences (IJB), 3(10), 82-91. https://doi.org/10.12692/ijb/3.10.82-91

Daun, D., Abelmoschus, G., Medik, L., Mamahit, L. P., Pertanian, J. T., \& Pertanian, F. (2010). Satu Senyawa Asam Organik Yang Diisolasi. Chem. Prog, 3(1), 1-4.

Jet S Mandey, Hendrawan Soetanto, Osfar Sjofjan, \& Bernat Tulung. (2014). Genetics characterization, nutritional and phytochemicals potential of gedi leaves (Abelmoschus manihot (L.) Medik) growing in the North Sulawesi of Indonesia as a candidate of poultry feed. Journal of Research in Biology, 4(2), 1276-1286. Retrieved from http://jresearchbiology.com/documents/RA0429.pdf

Kementrian Kesehatan RI Pusat Data dan Informasi Kesehatan. (2015). Data and Health Information of Cancer Situation. (1), 1-5. https://doi.org/10.1007/s13398-014-0173-7.2

Li, J., Zhang, J., \& Wang, M. (2016). Extraction of flavonoids from the flowers of abelmoschus manihot (1.) medic by modified supercritical co 2 extraction and determination of antioxidant and anti-adipogenic activity. Molecules, 21(7). https://doi.org/10.3390/molecules21070810

Siegel, R. L., Miller, K. D., \& Jemal, A. (2016). Cancer Siegel, R. L., Miller, K. D., \& Jemal, A. (2016). Cancer statistics, 2016. CA Cancer J Clin, 66(1), 7-30. https://doi.org/10.3322/caac.21332tatistics, 2016. CA Cancer J Clin, 66(1), 7-30. https://doi.org/10.3322/caac.21332

Taroreh, M., Raharjo, S., Hastuti, P., \& Murdiati, A. (2016). Antioxidative Activities of Various Fractions of Gedi's Leaf Extracts (Abelmoschus Manihot L. Medik). Agriculture and Agricultural Science Procedia, 9, 271-278. https://doi.org/10.1016/j.aaspro.2016.02.112

Waris, R., Dewi Pratiwi, E. A., \& Najib, A. (2016). Radical Scavenging Activity of Leaf Extract of Edible Hibiscus (Abelmoschus manihot (L.) Medik) Using 1,1-Diphenyl-2-Picryl Hydrazil (DPPH). International Journal of PharmTech Research, 9(5), 343-347.

World Health Organization|International Agency for Research on Cancer- Global Cancer Observatory. (2018). Age standardized (World) incidence rates, breast, all ages. 876, 1-2. Retrieved from http://gco.iarc.fr/today

Wu, L. L., Yang, X. B., Huang, Z. M., Liu, H. Z., \& Wu, G. X. (2007). In vivo and in vitro antiviral activity of hyperoside extracted from Abelmoschus manihot (L) medik. Acta Pharmacologica Sinica, 28(3), 404409. https://doi.org/10.1111/j.1745-7254.2007.00510.x 